\title{
Synthesis of Monolithic $\mathrm{Fe}_{2} \mathrm{O}_{3}-\mathrm{Al}_{2} \mathrm{O}_{3}$ Composite Aerogels via Organic Solvent Sublimation Drying
}

\author{
Lili Ren, Xueai Li, and Sumin Cui \\ School of Chemistry and Chemical Engineering, Southeast University, Nanjing 211189, China \\ Correspondence should be addressed to Lili Ren; renlily@126.com
}

Received 25 April 2016; Accepted 15 May 2016

Academic Editor: Ajayan Vinu

Copyright (C) 2016 Lili Ren et al. This is an open access article distributed under the Creative Commons Attribution License, which permits unrestricted use, distribution, and reproduction in any medium, provided the original work is properly cited.

Monolithic $\mathrm{Fe}_{2} \mathrm{O}_{3}-\mathrm{Al}_{2} \mathrm{O}_{3}$ composite aerogels have been prepared successfully via organic solvent sublimation drying method. The results show that a new phase forms when the right amount of ferric oxide is added to the alumina aerogel. From the TEM pictures we can see a shuttle-type structure with the length of about $15 \mathrm{~nm}$ forms, which leads to the high surface areas of composited aerogel.

\section{Introduction}

Aerogel is an extremely porous material prepared by using air replacing the liquid component of the wet gel [1-3]. Its unique structure makes it have extraordinary properties like low density, large porosity, low thermal conductivity, and high specific surface area, which lead it to receive much attention in a wide range of applications [4-8]. In particular alumina aerogel, which provides thermal insulation over a large temperature range and large specific surface area, would be a very useful material [9-12]. In order to make it better applied to some specific areas, we need to add other special materials to improve the characteristics of alumina aerogel. After adding iron oxide, alumina aerogel shows high magnetic strength and porosity. Thus $\mathrm{Fe}_{2} \mathrm{O}_{3}-\mathrm{Al}_{2} \mathrm{O}_{3}$ composite aerogel can be used as an absorbent, magnetic carrier, and high efficient reaction catalyst $[13,14]$. In addition, this composite aerogel has been used for selective hydrogenation reaction of sulfur dioxide because of good heat insulation performance [15]. But preparation of monolithic narrow pore size distribution mesoporous composite aerogel is very difficult. Recently we developed a new drying method to prepare inorganic oxide aerogels. That is organic solvents sublimation drying (OSSD) method [16]. This method can avoid the influence of surface tension of gas-liquid phase transformation during the drying process.
In this paper we applied it to prepare stable $\mathrm{Fe}_{2} \mathrm{O}_{3}-\mathrm{Al}_{2} \mathrm{O}_{3}$ composite aerogels with different ratio of iron oxide and investigate the effect of iron oxide on alumina aerogel through $\mathrm{X}$-ray diffraction (XRD), Fourier transform infrared (FT-IR) spectroscopy, nitrogen sorption isotherms, and transmission electron microscopy (TEM).

\section{Experimental}

2.1. Preparation. First, appropriate amount of ethanol and water was mixed and heated to $80^{\circ} \mathrm{C}$ in a beaker, and a certain amount of aluminum chloride hexahydrate (Sinopharm Chemical Reagent Co., Ltd.) was added with vigorous stirring until being dissolved. Then certain amount of hydrochloric acid (Shanghai Lingfeng Chemical Reagent Co., Ltd.) was added with stirring and reflux condensation for $4 \mathrm{~h}$. At last the sample was cooled to room temperature and the alumina clear sol was obtained.

The second step was the preparation of clear iron oxide sol. The detailed procedures are as follows: a certain amount of iron chloride (Sinopharm Chemical Reagent Co., Ltd.) was dissolved in anhydrous ethanol and then stirred at room temperature for 4 hours until getting Fe alcohol sol.

Then alumina sol and iron oxide sol were mixed according to the desired mole ratio of $\mathrm{Fe}$ and $\mathrm{Al}$ and reacted at room temperature for $5 \mathrm{~h}$ to get composite sol. A certain amount 


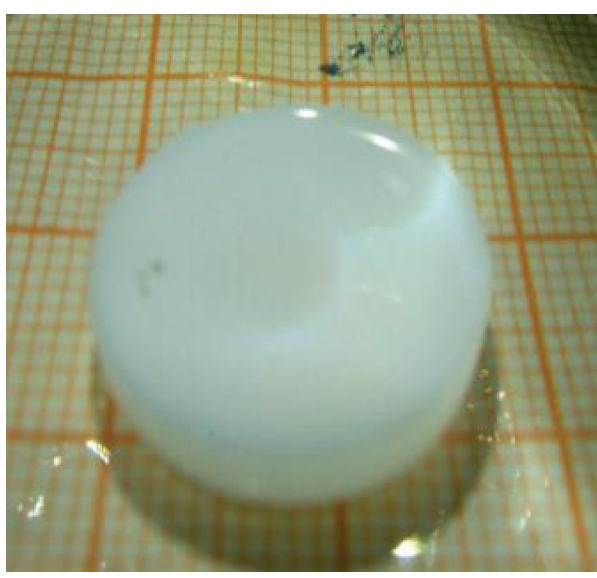

(a)

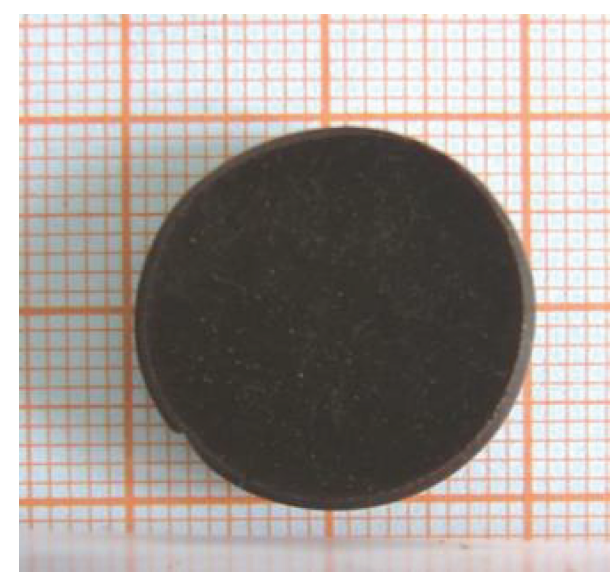

(b)

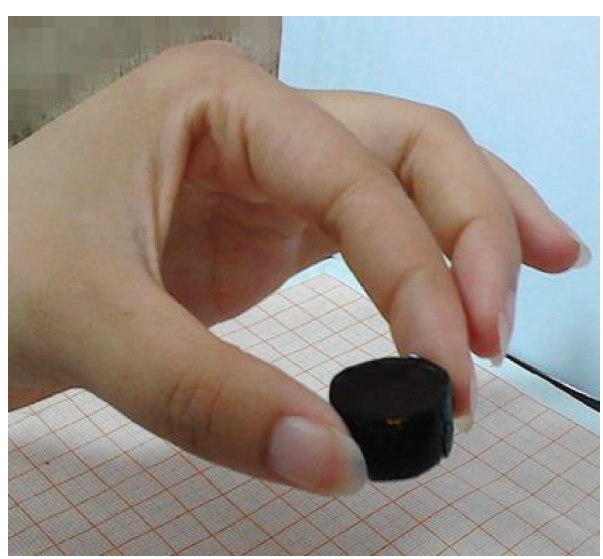

(c)

FIgURE 1: The picture of alumina aerogels (a), $\mathrm{Fe}_{2} \mathrm{O}_{3}$ aerogels (b), and $\mathrm{Fe}_{2} \mathrm{O}_{3}-\mathrm{Al}_{2} \mathrm{O}_{3}$ aerogel (c).

of epoxy propane (Shanghai Lingfeng Chemical Reagent Co., Ltd.) as a gelation agent was slowly added into the alumina, iron oxide, and composite sols, respectively, and then sealed at $25^{\circ} \mathrm{C}$ and let them turn into gels.

The obtained wet gel was dried through organic solvent sublimation drying technology (OSSD) [16]. The detailed procedure is as follows: the samples were aged in $\mathrm{EtOH}$ for $48 \mathrm{~h}$ at $50^{\circ} \mathrm{C}$ and then washed in $50 \%, 80 \%$, and $100 \%$ acetonitrile/EtOH (v/v) exchanged solvents for $24 \mathrm{~h}$ at $50^{\circ} \mathrm{C}$, respectively. After that, the wet gel was stored in a beaker and dried under the low vacuum condition.

2.2. Characterization. The pore size distribution and specific surface area of the samples were measured using a $\mathrm{N}_{2}$ adsorption analyzer (ASAP 2020). Before test, the samples were heated at $473 \mathrm{~K}$ in $10^{-6}$ Torr for $1 \mathrm{~h}$ for degassing. The Barrett-Joyner-Hollander (BJH) method was used to calculate the pore size distribution. The morphology and microstructures of the samples were characterized by a transmission electron microscope (TEM, JEOL-1230). Organic groups were investigated by a Fourier transform infrared spectroscope (FT-IR, TENSOR27). X-ray diffraction (XRD) data were recorded on D8-Discover (Bruker) using $\mathrm{Cu} \mathrm{K} \alpha$ radiation at a scanning speed of $2^{\circ} / \mathrm{min}$ within the $2 \theta$ range of $10^{\circ}-80^{\circ}$.

\section{Results and Discussions}

Through OSSD drying method, we successfully prepared monolithic alumina, $\mathrm{Fe}_{2} \mathrm{O}_{3}$, and $\mathrm{Fe}_{2} \mathrm{O}_{3}-\mathrm{Al}_{2} \mathrm{O}_{3}$ aerogels, as shown in Figure 1. All of the three aerogels are shiny and have no crack. The colour of $\mathrm{Fe}_{2} \mathrm{O}_{3}-\mathrm{Al}_{2} \mathrm{O}_{3}$ composite aerogel is shallower than pure iron oxide. We synthesized a series of $\mathrm{Fe}_{2} \mathrm{O}_{3}-\mathrm{Al}_{2} \mathrm{O}_{3}$ aerogels with different molar ratio of $\mathrm{Fe}$ and $\mathrm{Al}$ to investigate the effect of iron oxide on alumina aerogel.

Table 1 shows the BET surface area and pore structure parameters for different aerogels. From Table 1, we can find the pore volume and average pore diameter for $\mathrm{Fe}_{2} \mathrm{O}_{3}$ $\mathrm{Al}_{2} \mathrm{O}_{3}$ aerogels are between those of the $\mathrm{Al}_{2} \mathrm{O}_{3}$ and $\mathrm{Fe}_{2} \mathrm{O}_{3}$ aerogels, in addition to the BET surface area. When a little of iron oxides are added into $\mathrm{Al}_{2} \mathrm{O}_{3}$ aerogel, the surface area has a little change. With the increase of content of $\mathrm{Fe}_{2} \mathrm{O}_{3}$, 


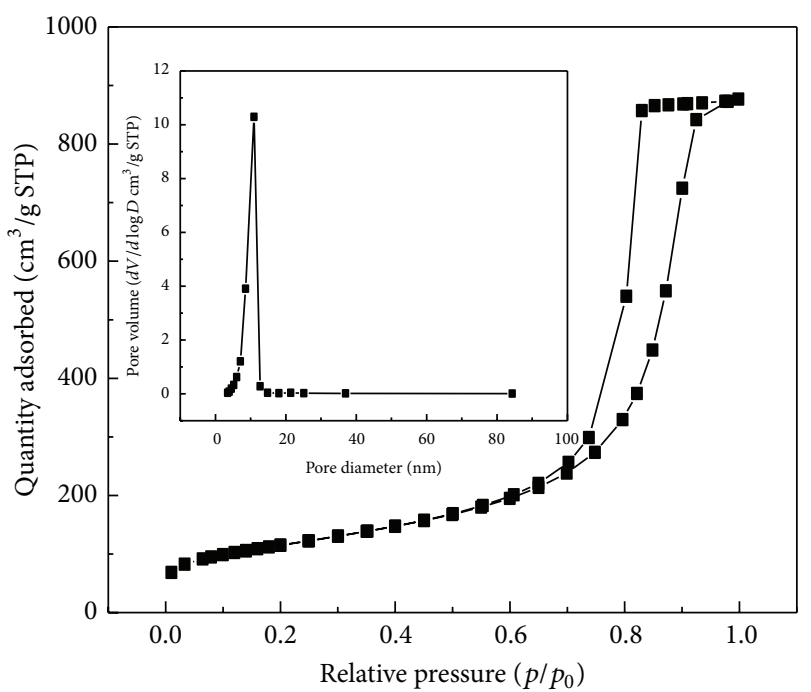

(a)

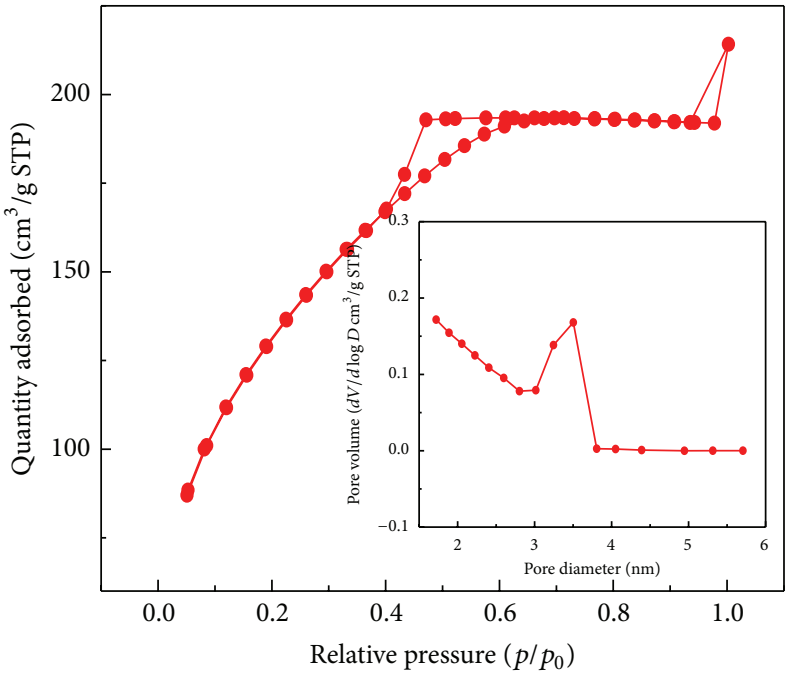

(b)

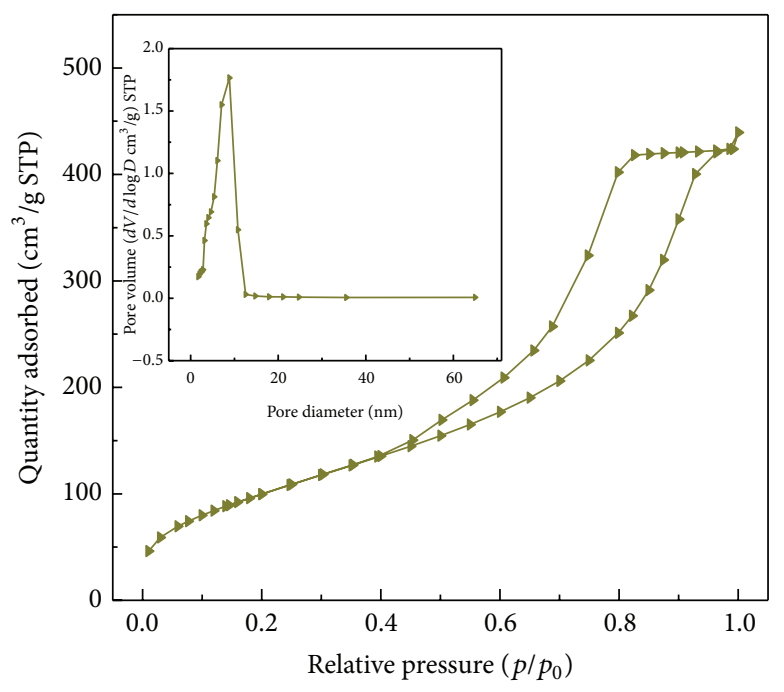

(c)

FIgURE 2: Nitrogen adsorption-desorption isotherms and pore size distribution of alumina aerogel (a), $\mathrm{Fe}_{2} \mathrm{O}_{3}$ aerogel (b), and $\mathrm{Fe}_{2} \mathrm{O}_{3}-\mathrm{Al}_{2} \mathrm{O}_{3}$ aerogel (c).

the surface area suddenly increases to $545.66 \mathrm{~m}^{2} \cdot \mathrm{g}^{-1}$. Then as the further increase of content of $\mathrm{Fe}_{2} \mathrm{O}_{3}$, the specific surface areas of composite aerogels begin to decrease little by little. So for $\mathrm{Fe}_{2} \mathrm{O}_{3}-\mathrm{Al}_{2} \mathrm{O}_{3}$ composite aerogels, appropriate proportion can make it have the largest specific surface area.

Figure 2 shows the nitrogen adsorption-desorption isotherms and pore size distribution of alumina aerogel, $\mathrm{Fe}_{2} \mathrm{O}_{3}$ aerogel, and $\mathrm{Fe}_{2} \mathrm{O}_{3}-\mathrm{Al}_{2} \mathrm{O}_{3}$ aerogel with 1:2 molar ratio of $\mathrm{Fe}$ to $\mathrm{Al}$, respectively. The pore structure and the BET surface area of $\mathrm{Fe}_{2} \mathrm{O}_{3}-\mathrm{Al}_{2} \mathrm{O}_{3}$ composite aerogel were close to those of pure alumina aerogel, rather than iron oxide which gave priority to micropores. The $\mathrm{Fe}_{2} \mathrm{O}_{3}-\mathrm{Al}_{2} \mathrm{O}_{3}$ composite aerogel and alumina aerogel had pronounced mesoporosity in the rage of 3-15 $\mathrm{nm}$ with a narrow pore size distribution, which made them have high internal surface areas.
Figure 3 shows the TEM pictures of three aerogels. From Figure 3 we can see that when floc structure $\mathrm{Fe}_{2} \mathrm{O}_{3}$ aerogel is added into thread-like structure alumina aerogel, shuttletype structure with the length of about $15 \mathrm{~nm}$ forms, which leads to the composite aerogel having the high surface area. At the same time, the figure also hints that a new form appears at composite aerogel, which is different from the pure alumina and $\mathrm{Fe}_{2} \mathrm{O}_{3}$ aerogel.

In order to further investigate the aerogels' composition, we carried out the FT-IR experiment, as shown in Figure 4. For alumina aerogel, boehmite is the main component for its infrared absorption peak at $1050 \mathrm{~cm}^{-1}$ and $616 \mathrm{~cm}^{-1}$. For $\mathrm{Fe}_{2} \mathrm{O}_{3}$ aerogel, the main composition should be $\mathrm{FeOOH}$ for its infrared absorption peak at $2920 \mathrm{~cm}^{-1}, 1105 \mathrm{~cm}^{-1}$, and $1404 \mathrm{~cm}^{-1}$. When $\mathrm{Fe}_{2} \mathrm{O}_{3}$ is added into alumina aerogel, 
TABLE 1: Pore structure parameters of alumina aerogels doped with various amounts of $\mathrm{Fe}_{2} \mathrm{O}_{3}$.

\begin{tabular}{ccccc}
\hline Samples & & BET $\left(\mathrm{m}^{2} \cdot \mathrm{g}^{-1}\right)$ & Pore volume $\left(\mathrm{cm}^{3} \cdot \mathrm{g}^{-1}\right)$ & Average pore diameter $(\mathrm{nm})$ \\
\hline $\mathrm{Al}_{2} \mathrm{O}_{3}$ & & 413.46 & 1.3562 & 11.7480 \\
\hline & $1: 10$ & 404.92 & 0.9007 & 8.8982 \\
& $1: 6$ & 408.27 & 0.8189 & 8.0231 \\
$\mathrm{Fe}_{2} \mathrm{O}_{3}-\mathrm{Al}_{2} \mathrm{O}_{3}$ & $1: 4$ & 419.45 & 0.8025 & 7.6527 \\
$\mathrm{~mol}(\mathrm{Fe}): \mathrm{mol}(\mathrm{Al})$ & $1: 2$ & 545.66 & 0.7229 & 3.6885 \\
& $3: 5$ & 471.15 & 0.7059 & 4.3027 \\
$\mathrm{Fe}_{2} \mathrm{O}_{3}$ & $4: 10$ & 429.89 & 0.7357 & 5.1163 \\
& $4: 5$ & 418.94 & 0.7620 & 5.2160 \\
& $1: 1$ & 376.07 & 0.6798 & 5.4163 \\
\hline
\end{tabular}

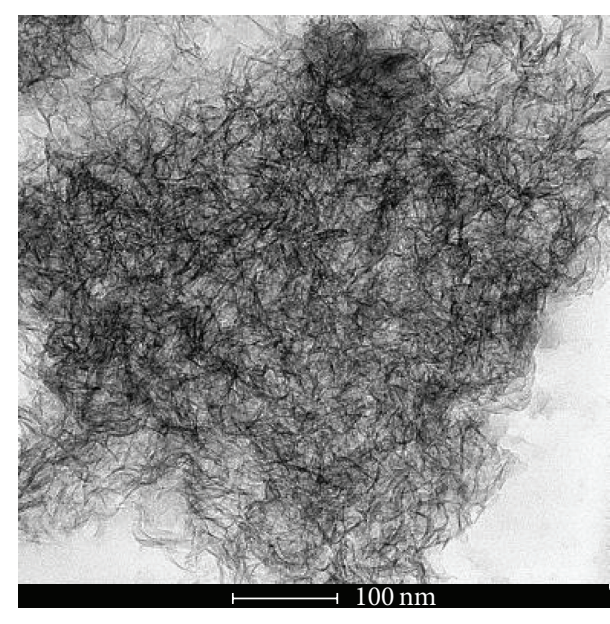

(a)

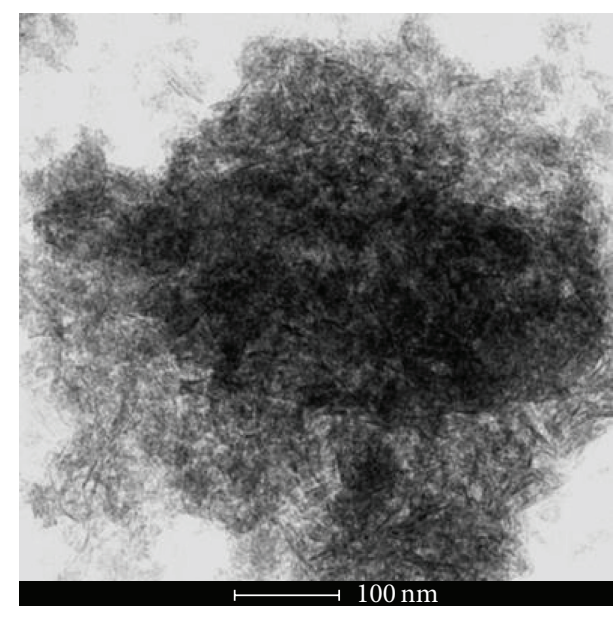

(b)

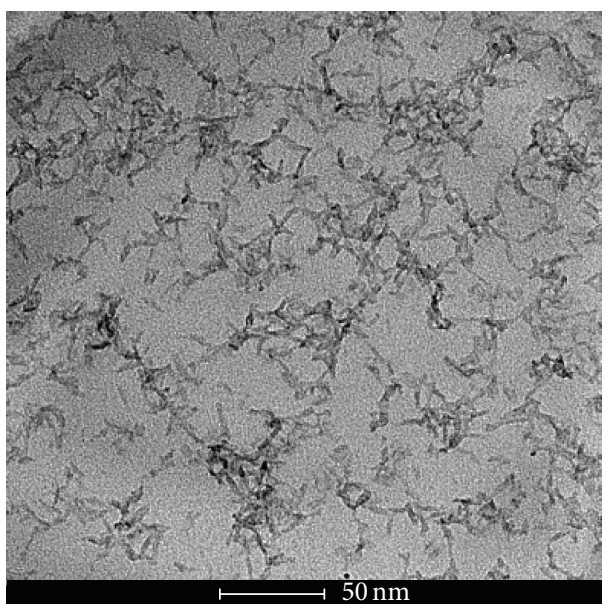

(c)

FIgURE 3: TEM photos for alumina aerogel (a), $\mathrm{Fe}_{2} \mathrm{O}_{3}$ aerogel (b), and $\mathrm{Fe}_{2} \mathrm{O}_{3}-\mathrm{Al}_{2} \mathrm{O}_{3}$ aerogel (c). 


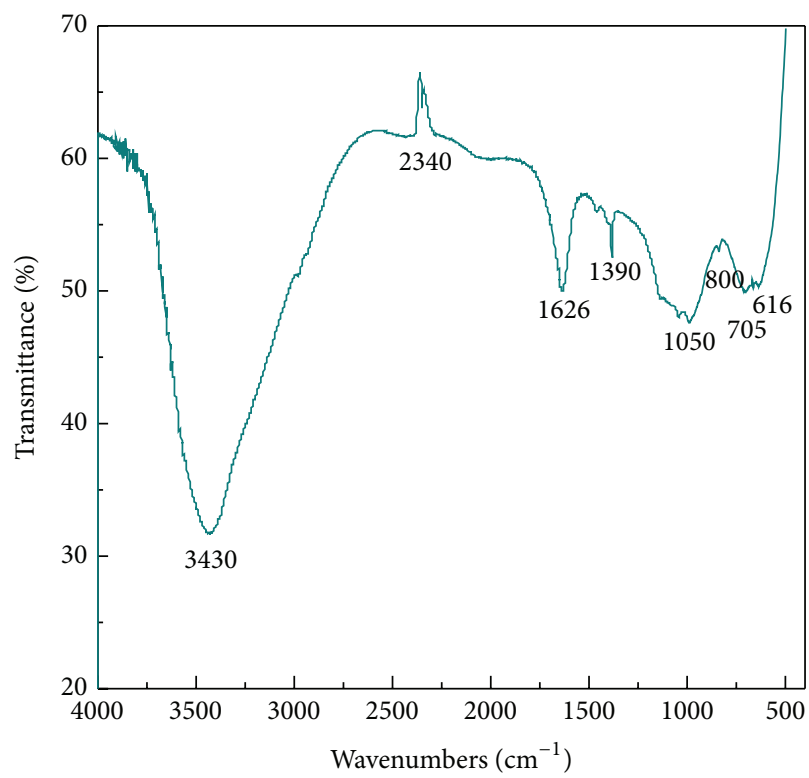

(a)

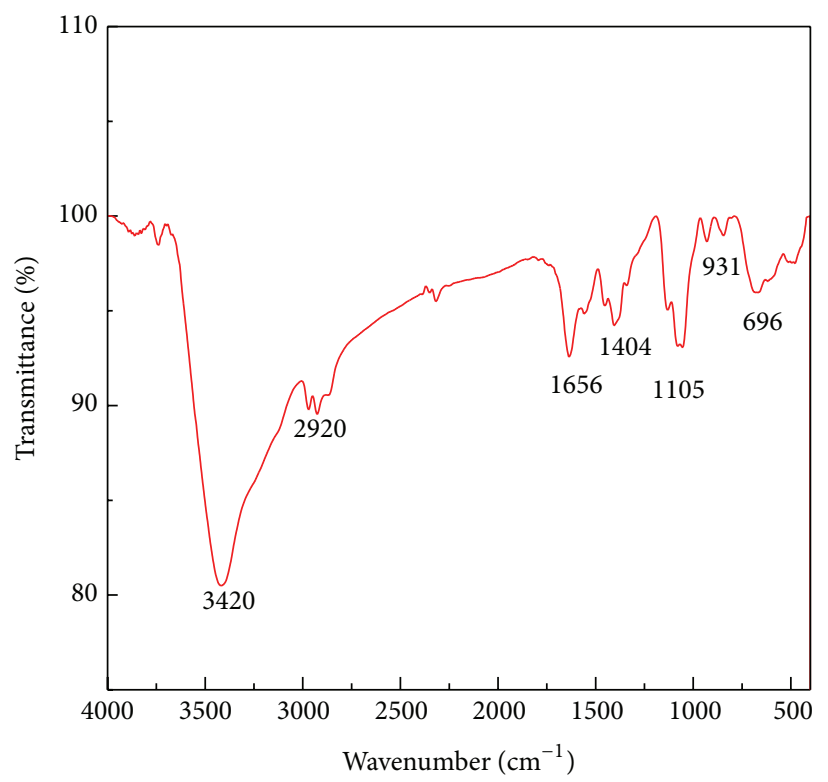

(b)

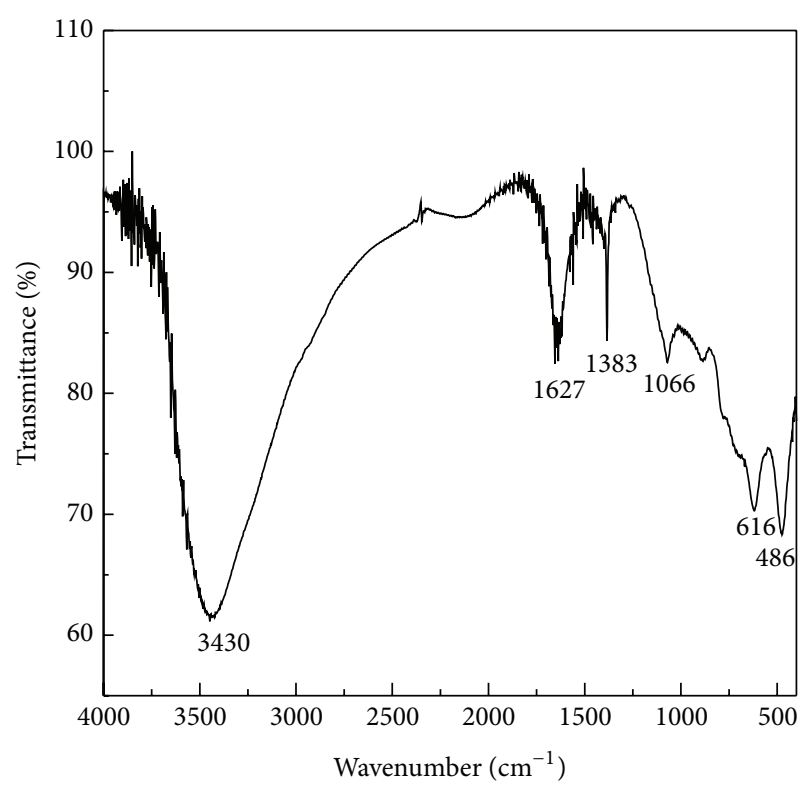

(c)

FIGURE 4: FT-IR spectrum of alumina aerogels (a), $\mathrm{Fe}_{2} \mathrm{O}_{3}$ aerogels (b), and $\mathrm{Fe}_{2} \mathrm{O}_{3}-\mathrm{Al}_{2} \mathrm{O}_{3}$ aerogel (c).

the IR spectra characteristic absorption peaks of boehmite and $\mathrm{FeOOH}$ are both reflected. In addition, there is an absorption peak at $496 \mathrm{~cm}^{-1}$, caused by the presence of the Al-O stretching vibration in $\mathrm{FeAl}_{2} \mathrm{O}_{4}$. Figure 5 shows a set of XRD patterns of above samples. The XRD patterns reveal the same information with the results of FT-IR experiment. For $\mathrm{Fe}_{2} \mathrm{O}_{3}-\mathrm{Al}_{2} \mathrm{O}_{3}$ aerogel, the peaks corresponding to $\mathrm{FeAl}_{2} \mathrm{O}_{4}$ appear obviously.

We think that $\mathrm{FeAl}_{2} \mathrm{O}_{4}$ is formed after mixing two kinds of sol. Hydrochloric acid was used in the preparation of alumina sol. When alumina sol was mixed with iron oxide sol, acidic condition would lead to some $\mathrm{FeAl}_{2} \mathrm{O}_{4}$ formation. Therefore, $\mathrm{FeAl}_{2} \mathrm{O}_{4}$ can be found in the characterization.

\section{Conclusions}

We successfully synergized monolithic alumina, $\mathrm{Fe}_{2} \mathrm{O}_{3}$, and $\mathrm{Fe}_{2} \mathrm{O}_{3}-\mathrm{Al}_{2} \mathrm{O}_{3}$ aerogels through OSSD drying method. Combined with IR spectra, TEM images, and pore structure parameters of aerogels, we found that the $\mathrm{Al}_{2} \mathrm{O}_{3}-\mathrm{Fe}_{2} \mathrm{O}_{3}$ composite aerogel with the appropriate proportion would form a new structure, which made it have the higher specific 


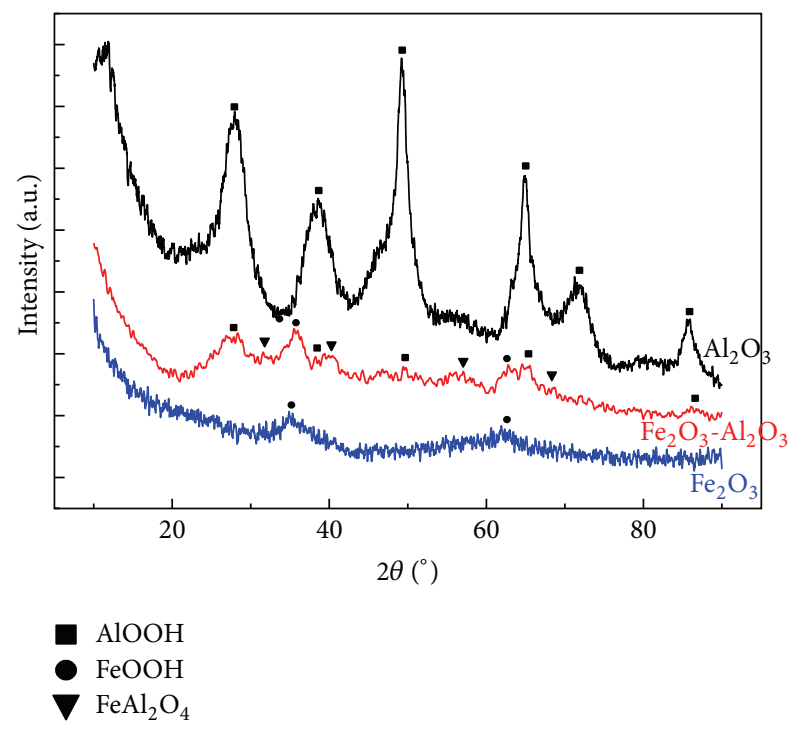

FIGURE 5: XRD patterns of alumina aerogels (black), $\mathrm{Fe}_{2} \mathrm{O}_{3}$ aerogels (blue), and $\mathrm{Fe}_{2} \mathrm{O}_{3}-\mathrm{Al}_{2} \mathrm{O}_{3}$ aerogel (red).

surface area than the pure $\mathrm{Al}_{2} \mathrm{O}_{3}$ and $\mathrm{Fe}_{2} \mathrm{O}_{3}$ aerogels. And its particle size focused on about $15 \mathrm{~nm}$ and average pore diameter was about $4 \mathrm{~nm}$.

\section{Competing Interests}

The authors declare that they have no competing interests.

\section{Acknowledgments}

This work was partially supported by Nature Science Foundation of Jiangsu Province of China (BK20151408) and National Nature Science Foundation of China (21206018).

\section{References}

[1] S. S. Kistler, "Coherent expanded aerogels and jellies," Nature, vol. 127, no. 3211, p. 741, 1931.

[2] H. D. Gesser and P. C. Goswami, "Aerogels and related porous materials," Chemical Reviews, vol. 89, no. 4, pp. 765-788, 1989.

[3] N. Husing and U. Schubert, "Aerogels," in Ullmann's Encyclopedia of Industrial Chemistry, John Wiley \& Sons, 2002.

[4] J. Fricke and T. Tillotson, "Aerogels: production, characterization, and applications," Thin Solid Films, vol. 297, no. 1-2, pp. 212-223, 1997.

[5] A. C. Pierre and G. M. Pajonk, "Chemistry of aerogels and their applications," Chemical Reviews, vol. 102, no. 11, pp. 4243-4265, 2002.

[6] M. A. Aegerter, N. Leventis, and M. M. Koebel, Aerogels Handbook, Springer, New York, NY, USA, 2011.

[7] J. P. Randall, M. A. B. Meador, and S. C. Jana, "Tailoring mechanical properties of aerogels for aerospace applications," ACS Applied Materials and Interfaces, vol. 3, no. 3, pp. 613-626, 2011.
[8] S. M. Jung, H. Y. Jung, M. S. Dresselhaus, Y. J. Jung, and J. Kong, "A facile route for 3D aerogels from nanostructured 1D and 2D materials," Scientific Reports, vol. 2, article 849, 2012.

[9] J. F. Poco, J. H. Satcher Jr., and L. W. Hrubesh, "Synthesis of high porosity, monolithic alumina aerogels," Journal of NonCrystalline Solids, vol. 285, no. 1-3, pp. 57-63, 2001.

[10] Z.-X. Sun, T.-T. Zheng, Q.-B. Bo, M. Du, and W. Forsling, "Effects of calcination temperature on the pore size and wall crystalline structure of mesoporous alumina," Journal of Colloid and Interface Science, vol. 319, no. 1, pp. 247-251, 2008.

[11] L. Wu, Y. Huang, Z. Wang, L. Liu, and H. Xu, "Fabrication of hydrophobic alumina aerogel monoliths by surface modification and ambient pressure drying," Applied Surface Science, vol. 256, no. 20, pp. 5973-5977, 2010.

[12] W. Bao, F. Guo, H. Zou, S. Gan, X. Xu, and K. Zheng, "Synthesis of hydrophobic alumina aerogel with surface modification from oil shale ash," Powder Technology, vol. 249, pp. 220-224, 2013.

[13] M. A. Karakassides, D. Gournis, A. B. Bourlinos, P. N. Trikalitis, and T. Bakas, "Magnetic $\mathrm{Fe}_{2} \mathrm{O}_{3}-\mathrm{Al}_{2} \mathrm{O}_{3}$ composites prepared by a modified wet impregnation method," Journal of Materials Chemistry, vol. 13, no. 4, pp. 871-876, 2003.

[14] H. Fan, Q. Xu, Y. Guo, and Y. Cao, " $\mathrm{Al}_{2} \mathrm{O}_{3} / \mathrm{Fe}_{2} \mathrm{O}_{3}$ mesoporous composite prepared with activated carbon template in supercritical carbon dioxide," Industrial and Engineering Chemistry Research, vol. 45, no. 14, pp. 5009-5012, 2006.

[15] W. J. Xi, R. L. Peng, W. Wu, N. Li, S. Wang, and S. Johansson, " $\mathrm{Al}_{2} \mathrm{O}_{3}$ nanoparticle reinforced $\mathrm{Fe}$-based alloys synthesized by thermite reaction," Journal of Materials Science, vol. 47, no. 8, pp. 3585-3591, 2012.

[16] L. Ren, S. Cui, F. Cao, and Q. Guo, "An easy way to prepare monolithic inorganic oxide aerogels," Angewandte ChemieInternational Edition, vol. 53, no. 38, pp. 10147-10149, 2014. 

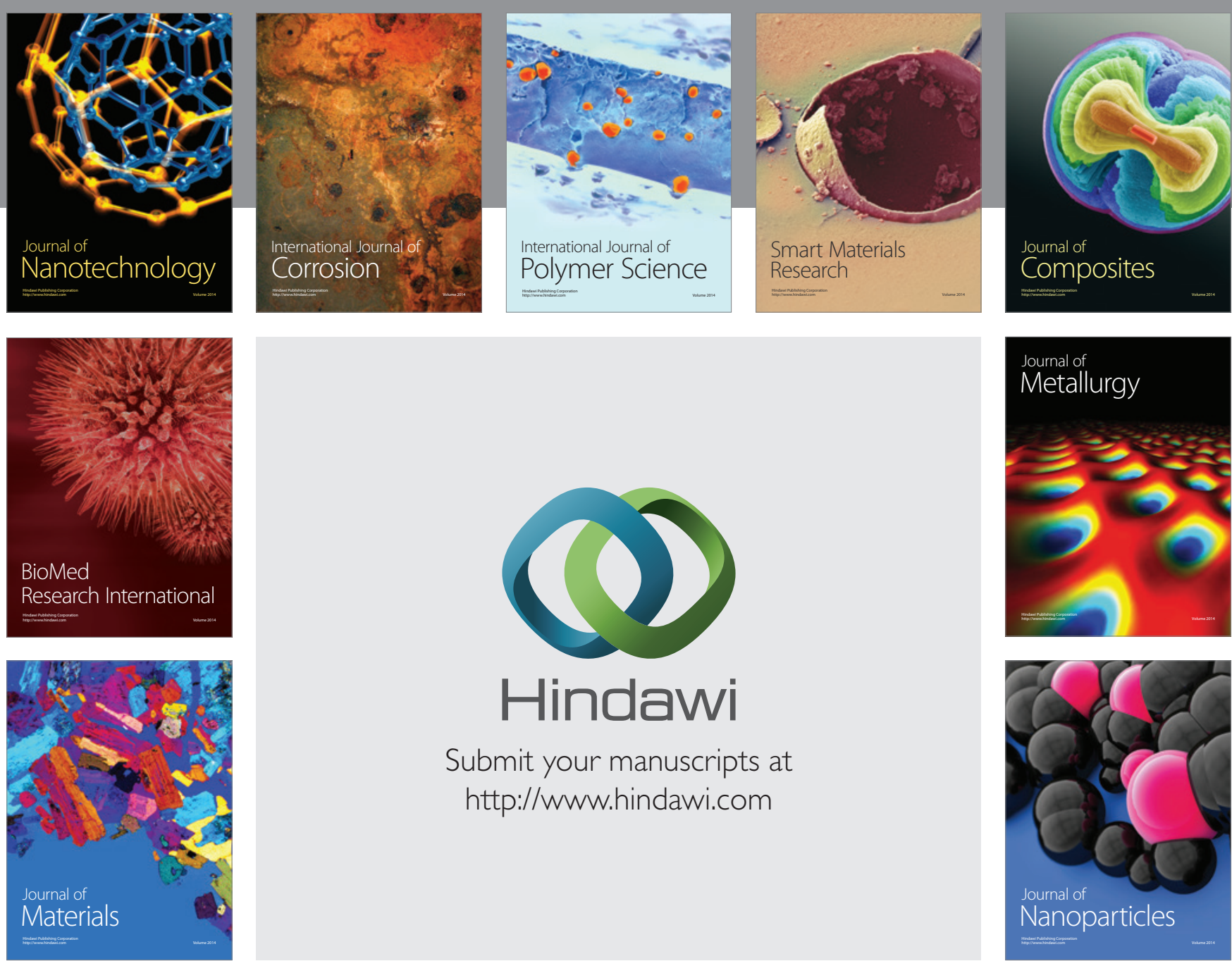

\section{Hindawi}

Submit your manuscripts at

http://www.hindawi.com

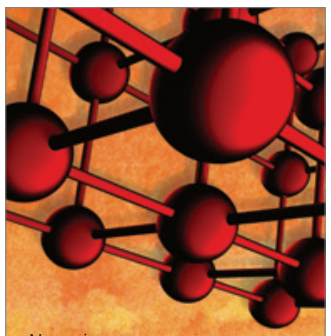

Materials Science and Engineering
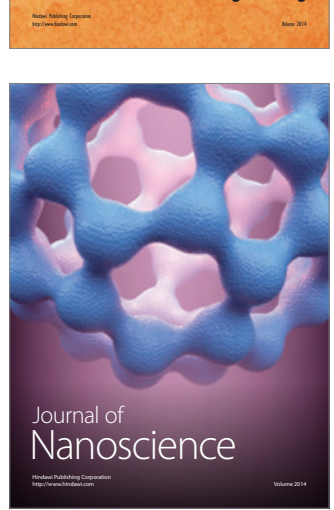
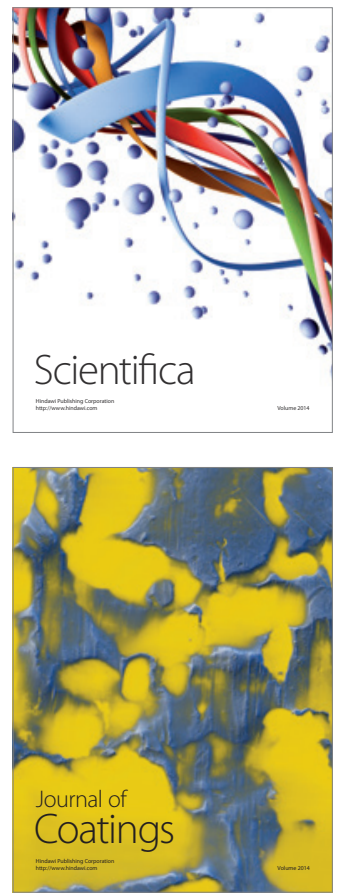
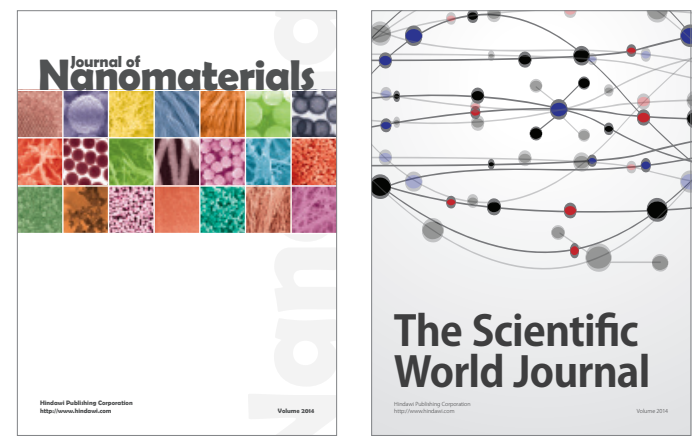

The Scientific World Journal
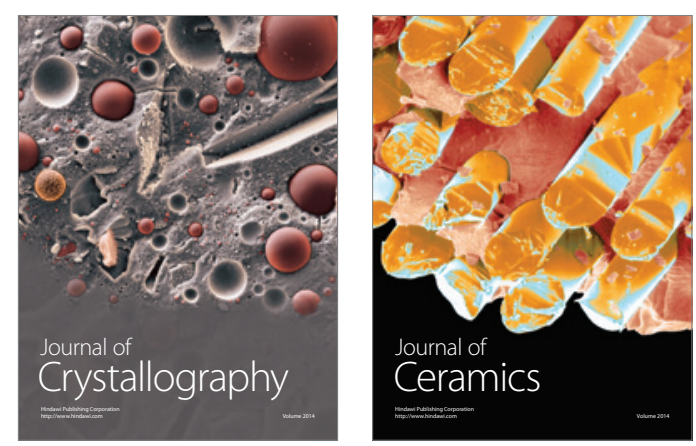
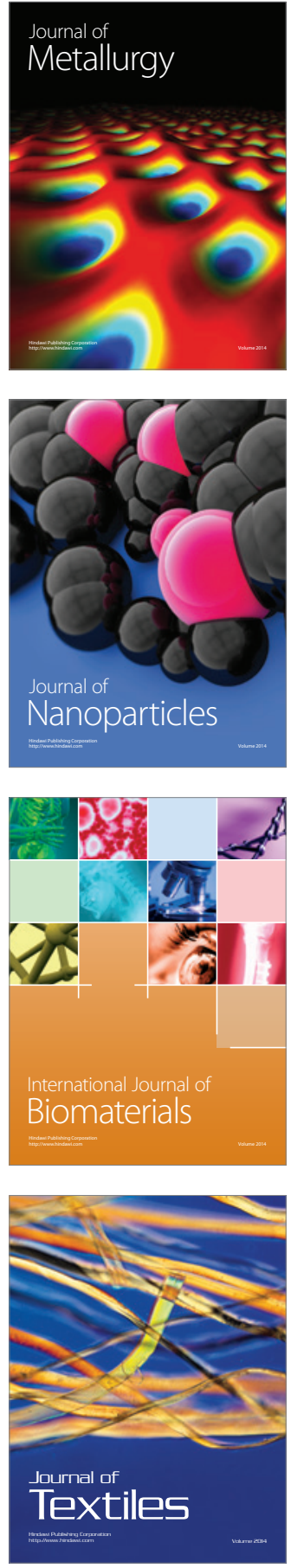